\title{
Anisotropic Electronic Transport of Graphene on a Nano-Patterned Substrate
}

\author{
H. M. W. Khaliil ${ }^{a}$ O. Kelekci ${ }^{a}, H . N^{a *}$, and Y. H. Xie ${ }^{b}$ \\ ${ }^{a}$ Department of Physics and Graphene Research Institute, Sejong University, Seoul 143-747, \\ ${ }^{b}$ Department of Materials Science and Engineering, University of California, Los Angeles, CA, USA 90095 \\ (Received August 3, 2012, Revised September 14, 2012, Accepted September 17, 2012)
}

We report on the measurements of electronic transport properties of CVD graphene placed on a pre-patterned substrate with periodic nano trenches. A strong anisotropy has been observed between the transport parallel and perpendicular to the trenches. Characteristically different weak localization corrections have been also observed when the transport was perpendicular to the trench, which is interpreted as due to a density inhomogeneity generated by the potential modulations.

Keywords : Graphene, Nano trench, Anisotropy, Weak localization

\section{Introduction}

Graphene has unique electronic properties resulting from its linear dispersions [1,2]. Since its first discovery by mechanical exfoliation method, there are several other methods developed for the production of graphene such as an epitaxial growth on $\mathrm{SiC}$ [3] or a CVD growth on a metal foil [4-6]. Many of the electronic measurements were done for a graphene placed on a $\mathrm{Si}$ substrate covered with a $300 \mathrm{~nm}$ thick $\mathrm{SiO}_{2}$. The effects of substrates on the electronic transport are especially important, and it was known that the mobility can be greatly enhanced if the graphene is suspended [7]. This also provides a possibility that an interesting transport characteristic can be observed on a different substrate other than $\mathrm{SiO}_{2}$. For example, there have been studies which incorporated a high-K material or hexagonal boron nitride on the substrate to identify the scattering mechanisms that limit the mobility [8-11]. Another way of modifying the substrate is to make nano-sized patterns with various geometries. It can provide separate regions on the substrate with different impurity profiles. With the common use of the substrate as a backgate, the nano patterns will also generate a potential modulation and could result in a density inhomogeneity of the carriers.

In this study, we have measured the electronic transport of graphene placed on a substrate which had been pre-patterned with periodic nano trenches. Depending on the relative direction of the electric current to that of the trenches, a strong anisotropy has been observed. The carrier mobility was much lower when the current was directed perpendicular to the trenches. In addition, quantum corrections to the resistivity due to the weak localization showed a different behavior so that the intervalley scattering time

\footnotetext{
* [E-mail] hnoh@sejong.ac.kr
} 
was higher than the phase coherence time, which is believed to result from the potential modulation formed by the periodic trenches.

\section{Experimental Method}

In Fig. 1(a), the processing steps of the sample are shown. To fabricate periodic nano trenches, e-beam lithography was applied on an oxidized Si substrate, and the $\mathrm{SiO}_{2}$ was etched by a dry etching method. There are two different regions of trenches, each with $30 \mu \mathrm{m} \times 15 \mu \mathrm{m}$ in area. One has trenches parallel to the longitudinal direction of the Hall bar, and the other perpendicular. Both the width and the gap

\section{(a) Nano trench}

Graphene transfer
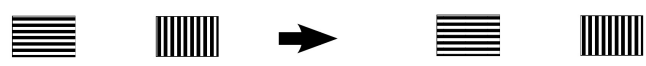

Hall bar patterning

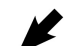

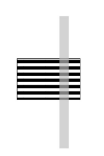

(b)
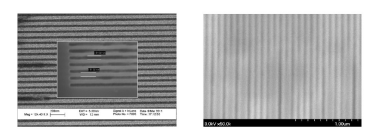

(c)

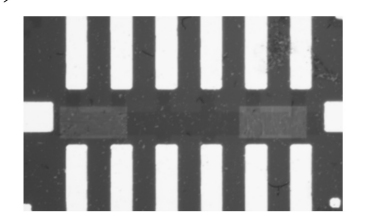

Figure 1. (a) Sample fabrication process. Nano trenches are made on a $\mathrm{SiO}_{2} / \mathrm{Si}$ substrate followed by a graphene transfer. Then, Hall bar patterns are defined on the graphene and metal contacts are made. (b) SEM images of the trenches. One is parallel to the longitudinal direction of the Hall bar (left), and the other is perpendicular (right). (c) Optical microscope image of the finished device.

of the trenches are $50 \mathrm{~nm}$. The depth of the trenches, i.e. the thickness of the oxide is $100 \mathrm{~nm}$. After the trench fabrication, graphene was transferred onto the substrate. The graphene used in the study was grown by $\mathrm{CVD}$ on a $\mathrm{Cu}$ foil. To transfer the graphene, we first covered the graphene with PMMA and then etched $\mathrm{Cu}$ foil using $\mathrm{Fe}_{2} \mathrm{Cl}_{3}$ solution. After cleaning with DI water, we transferred the PMMA/graphene onto the substrate, and then removed the PMMA by acetone. The graphene was then fabricated into a Hall bar shaped device for electric measurements. A photolithography process was used to define the Hall bar pattern followed by an oxygen plasma etching. The width of the Hall bar is $10 \mu \mathrm{m}$. Another photolithography was used to define the metal contact patterns and $\mathrm{Ti} / \mathrm{Pd} / \mathrm{Au}$ was thermally evaporated followed by a lift-off process. The Hall bar has three different regions for measurements. Two of them are on the trenches, parallel and perpendicular, and the other has no trenches. This makes a direct comparison of the transport characteristics between different regions possible in a single device. In Fig. 1(b), we show an SEM image of the trenches before the graphene transfer, and in Fig. 1(c) an optical microscope image of the finished sample. A lock-in amplifier was used for standard 4-probe measurements of resistivity and Hall effect. The measurements were done at low temperatures using a $\mathrm{He}-3$ cryostat.

\section{Results and Discussion}

In Fig. 2(a) we show the measured resistivity $(\rho)$ as a function of the gate voltage $\left(V_{g}\right)$ for the three different regions. The resistivity for the perpendicular trench region is much higher than the other two regions, about 7 to 10 times. Dirac point is observed around $V_{g}=+3 \mathrm{~V}$ for the no trench region and $+4 \mathrm{~V}$ for the perpendicular and the parallel trench regions. To limit the gate leakage current below $1 \mathrm{nA}, V_{g}$ was 

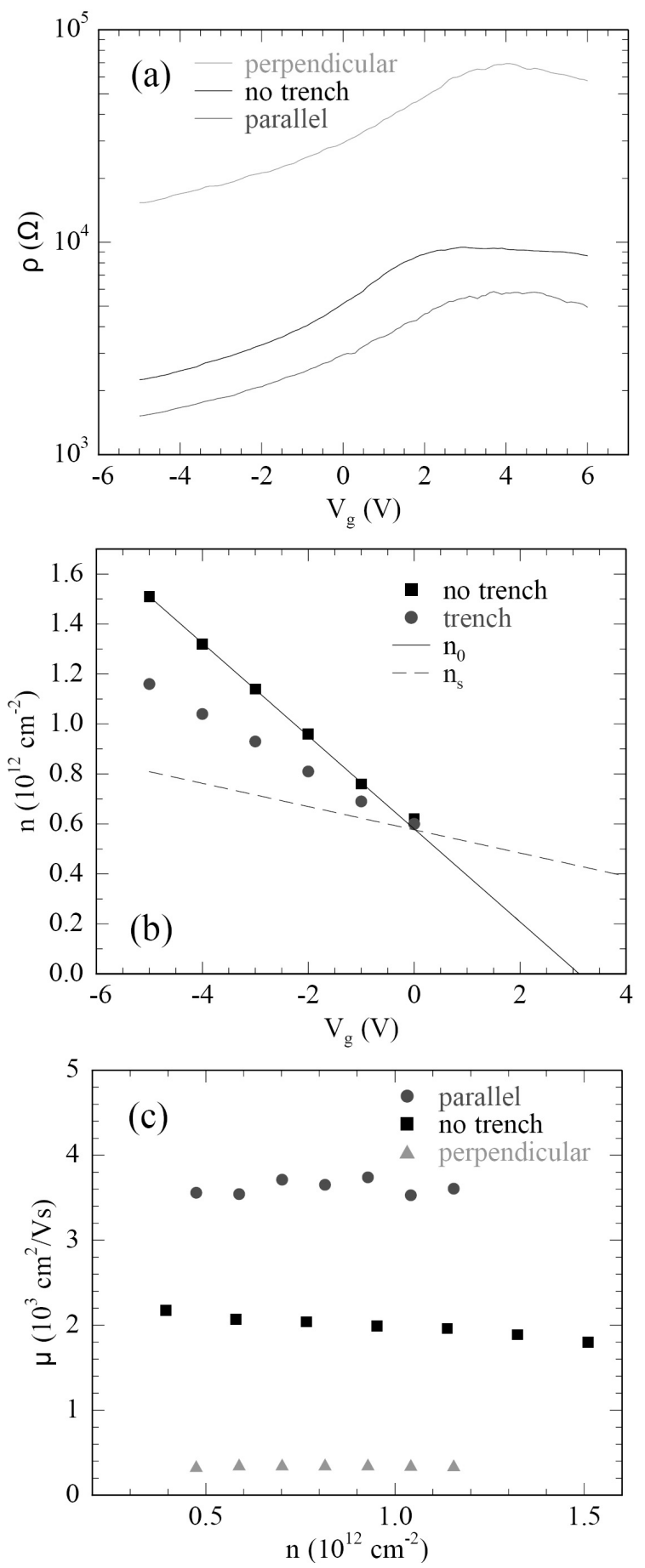

Figure 2. (a) Resistivity as a function of the gate voltage. (b) Hole density as a function of the gate voltage. The density for the no trench region is obtained from the Hall measurement and the best linear fit (solid line) of its gate voltage dependence is assumed to represent $n_{0}$. The expected $n_{s}$ is given by the dashed line. The density for the trench region is given by $\left(n_{0}+n_{s}\right) / 2$. (c) Mobility as a function of hole density. varied only between $-5 \mathrm{~V}$ and $+6 \mathrm{~V}$, which made the carrier type holes for most of the gate voltage range, and we will focus on the transport of holes in the following. We note that the graphene placed on the trench region consists of two parts, suspended part and the part supported by the substrate material, which have different carrier densities and mobilities. In the parallel trench region each part is continuous from the source to the drain of the current forming a parallel connection, while in the perpendicular trench region each part is connected repeatedly in series. The resistivity in the parallel trench region is supposed to be given by $2 \rho_{0} \rho_{s} /\left(\rho_{0}+\rho_{s}\right)$ and that in the perpendicular trench region by $\left(\rho_{0}+\rho_{s}\right) / 2$, where $\rho_{0}$ and $\rho_{s}$ are the resistivities of the supported part and the suspended part, respectively. Assuming that $\rho_{0}$ is the same as what is shown in Fig. 2(a) for the no trench region, we can extract $\rho_{s}$ from the data for the other two regions. With the measured resistivity in the parallel trench region, $\rho_{s}$ is estimated to be about $30 \sim 50 \%$ of $\rho_{0}$. On the other hand, if we use the resistivity in the perpendicular trench region, we get $\rho_{s}$ to be about 10 times larger than $\rho_{0}$. Since it is known that the mobility of the suspended graphene is larger than the supported one, the result extracted from the perpendicular trench region seems unusual.

The hole density $(n)$ as a function of $V_{g}$ in the no trench region extracted from the Hall measurements is shown in Fig. 2(b) by the black symbols. The gating efficiency obtained from the slope is consistent with that expected for a $100 \mathrm{~nm}$-thick $\mathrm{SiO}_{2}$. For the other two regions, the Hall measurements cannot be used to extract the carrier density due to the inhomogeneity in the system. By assuming that the hole density in the supported part $\left(n_{0}\right)$ is the same as that in the no trench region and the hole density in the suspended part $\left(n_{s}\right)$ is equal to $n_{0}$ when $V_{g}=0$ and determined by a gating efficiency that is 4 times smaller, the dielectric constant ratio of air to $\mathrm{SiO}_{2}$, we can estimate the hole density in the trench region as $\left(n_{0}+n_{s}\right) / 2$, 
which is shown by the red symbols. In Fig. 2(c), the mobility as a function of the hole density is shown for the three regions. The mobility in the no trench region is comparable to that reported for a good CVD graphene by other groups. With a simple model of series and parallel connections of conductors, the mobilities of the parallel trench region $\left(\mu_{\|}\right)$and the perpendicular trench region $\left(\mu_{\perp}\right)$ can be shown to be $\mu_{\|}=\left(n_{0} \mu_{0}+n_{s} \mu_{s}\right) /\left(n_{0}+n_{s}\right) \quad$ and $\quad \mu_{\perp}=4 n_{0} n_{s} \mu_{0} \mu_{s} /\left(n_{0}+n_{s}\right)$ $\left(n_{0} \mu_{0}+n_{s} \mu_{s}\right)$, where $\mu_{0}$ and $\mu_{s}$ are the mobilities in the supported and the suspended parts, respectively. $\mu_{0}$ should be the same as the mobility in the no trench region. By assuming that $\mu_{s}>\mu_{0}$, we expect that $\mu_{\|} \geq \mu_{\perp}>\mu_{0}$. Since $\mu_{\|}>\mu_{0}$ is satisfied in our data, we can use the measured values of $\mu_{\|}$to estimate $\mu_{s}$ and we get $\mu_{s}=10,000 \mathrm{~cm}^{2} / \mathrm{Vs}$. This value is about 5 times larger than $\mu_{0}$. On the other hand, the measured mobility in the perpendicular trench region is much lower than $\mu_{0}$, opposite to the expectation. The smallness of $\mu_{\perp}$ is very intriguing, and some additional mechanisms might be playing a role beyond the simple model of series connection.

We note that the supported and the suspended parts in the trench region will provide different impurity potentials for the carrier transport since the charged impurities in $\mathrm{SiO}_{2}$, the predominant source of the impurities, are absent for the suspended part. This will make a modulation in the impurity potential profile. In addition, the gate voltages in the presence of trenches will induce an electrostatic potential modulation. The carriers in the perpendicular trench region will cross such a potential landscape to transport from the source to the drain with some scattering from the potential barriers. Even though a similar potential modulation will be induced in the parallel trench region, the carriers can transport within a same potential profile area and do not need to cross the potential landscape. This characteristically different transport can result in the observed differences in the mobility. We note that a reduction in the mobility by $1 \sim 2$ orders of magnitude compared with a pristine graphene has been previously observed in a graphene nanomesh device where the carriers experience scattering by the hard walled potential of nano holes fabricated directly on the graphene [12].

To explore the effects of such potential modulations on the quantum transport, we measured the low field magnetoresistance and studied the weak localization corrections. Weak localization negative magnetoresistance in graphene has been observed in many graphene samples if the intervalley scattering makes a transition to a different chiral state possible [13-15]. In graphene, the magnetoresistance is given by the formula developed by McCann et al. [16]

$$
\frac{\Delta \rho}{\rho}=-\frac{e^{2} \rho}{\pi h}\left[F\left(\frac{B}{B_{\phi}}\right)-F\left(\frac{B}{B_{\phi}+2 B_{i}}\right)-2 F\left(\frac{B}{B_{\phi}+B_{i}+B_{*}}\right)\right], \text { Eq. (1) }
$$

where $F(z)=\ln z+\Psi(1 / 2+1 / z), B_{\phi, i, *}=(\hbar / 4 D e)\left(1 / \tau_{\phi, i, *}\right)$, $\Psi$ is Digamma function, and $\tau_{\phi, i, *}$ are phase coherence time, intervalley scattering time, and intravalley scattering time, respectively. In Fig. 3(a), the magnetoresistances measured in the three different regions for $V_{g}=-3 \mathrm{~V}$ are shown. All of them show a clear negative magnetoresistance due to the weak localization. Best fits with Eq. (1) are shown by the dashed lines. Characteristically different behavior of the magnetoresistance is observed depending on the regions. The initial decrease of the resistivity which is mostly determined by the phase coherence time is about the same for all three regions. On the other hand, the magnetoresistance above $0.2 \mathrm{~T}$ is different, suggesting different intervalley or intravalley scattering times for the three regions. It was found that $\tau_{*}$ is always much smaller than $\tau_{\phi}$ or $\tau_{i}$ so the third term gives negligible effects.

In Fig. 3(b) and (c), the extracted $\tau_{\phi}$ and $\tau_{i}$ are shown as a function of the hole density. While $\tau_{\phi}$ 's for the three regions are of comparable magnitude, $\tau_{i}$ depends strongly on the regions. It is the smallest in the no trench region, a little larger in the parallel trench 
region, and then becomes the largest in the perpendicular trench region. In the perpendicular trench region, $\tau_{i}$ is even larger than $\tau_{\phi}$. An increase of $\tau_{i}$ compared with $\tau_{\phi}$ was also observed in other studies close to the Dirac point, and it was argued that the formation of electron-hole puddles was a possible cause for that $[13,15]$. Transport across a $p-n$ junction in graphene is known to be highly transparent for normal incidence due to the Klein tunneling [17], and such tunneling happens without the chirality-breaking intervalley scattering. Therefore, the formation of electron-hole puddles and the accompanying $\mathrm{p}-\mathrm{n}$ junctions will make some conduction channels through the Klein tunneling and will make the effective intervalley scattering time longer. In our data for the perpendicular trench region, $\tau_{i}$ is larger than $\tau_{\phi}$ even far from the Dirac point, where the effects of elec-
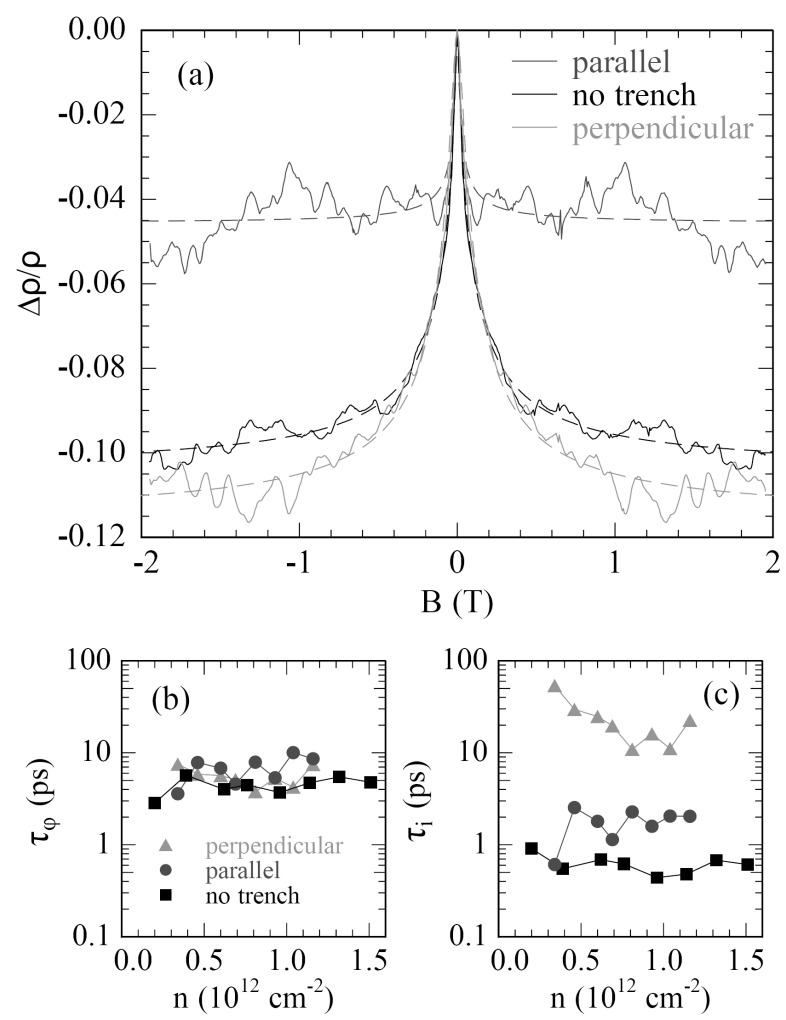

Figure 3. (a) Negative magnetoresistance in the three regions for $V_{g}=-3 \mathrm{~V}$. Best fits to Eq. (1) are shown by the dashed lines. The extracted $T_{\phi}$ and $T_{\mathrm{i}}$ are shown as a function of hole density in (b) and (c), respectively. tron-hole puddles are supposed to be less important. Nevertheless, the modulation of potential profile will yield a density inhomogeneity and could generate effective barriers for the carrier transport and some electron-hole puddles. A presence of transport channel by the Klein tunneling through such barriers could result in an increase of $\tau_{i}$.

\section{Conclusion}

We have studied the electronic transport properties of graphene placed on periodic nano trenches. Depending on the direction of the current relative to the direction of the potential modulation generated by the trenches, a strong anisotropy in the mobility and the weak localization corrections have been observed. Based on the simple model of parallel connections of the suspended part and the supported part, we could extract the mobility of the suspended part from the measured mobility of the parallel trench region and the no trench region. The mobility in the perpendicular trench region could not be understood in the simple model of series connections. In all three regions, negative magnetoresistance due to the weak localization has been observed clearly and the extracted phase coherence time was of the same magnitude. The intervalley scattering time, on the other hand, increases in order of no trench region, parallel trench region, and perpendicular trench region. The increase of the intervalley scattering time is related to the presence of conduction channels by the Klein tunneling through potential barriers.

\section{Acknowledgments}

This work was supported by the Korea Research Foundation Grant funded by the Korean Government (MOEHRD, Basic Research Promotion Fund) (KRF- 
2007-331-C00109), and by Priority Research Centers

Program (2010-0020207) through the National

Research Foundation of Korea (NRF) funded by the Ministry of Education, Science and Technology.

\section{References}

[1] A. K. Geim and K. S. Novoselov, Nature Mater. 6, 183 (2007).

[2] S. Das Sarma, S. Adam, E. H. Hwang, and E. Rossi, Rev. Mod. Phys. 83, 407 (2011).

[3] C. Berger, Z. Song, T. Li, X. Li, A. Y. Ogbazghi, R. Feng, Z. Dai, A. N. Marchenkov, E. H. Conrad, P. N. First, and W. A. de Heer, J. Phys. Chem. B 108, 19912 (2004).

[4] Q. Yu, J. Lian, S. Siriponglert, H. Li, Y. P. Chen, and S. S. Pei, Appl. Phys. Lett. 93, 113103 (2008).

[5] Y. Lee, S. Bae, H. Jang, S. Jang, S. E. Zhu, S. H. Sim, Y. I. Song, B. H. Lee, and J. H. Ahn, Nano Lett. 10, 490 (2010).

[6] H. Cao, Q. Yu, L. A. Jauregui, J. Tian, W. Wu, Z. Liu, R. Jalilian, D. K. Benjamin, Z. Jiang, J. Bao, S. S. Pei, and Y. P. Chen, Appl. Phys. Lett. 96, 122106 (2010).

[7] K. I. Bolotin, K. J. Sikes, Z. Jiang, M. Klima, G. Fudenberg, J. Hone, P. Kim, and H. L. Stormer, Solid. State. Commun. 146, 351 (2008).
[8] A. Konar, T. Fang, and D. Jena, Phys. Rev. B 82, 115452 (2010).

[9] X. Li, E. A. Barry, J. M. Zavada, M. Buongiorno, and K. W. Kim, Appl. Phys. Lett. 97, 232105 (2010).

[10] A. Betti, G. Fiori, and G. Iannaccone, Appl. Phys. Lett. 98, 212111 (2011).

[11] C. R. Dean, A. F. Young, I. Meric, C. Lee, L. Wang, S. Sorgenfrei, K. Watanabe, T. Taniguchi, P. Kim, K. L. Shepard, and J. Hone, Nature Nanotech. 5, 722 (2010).

[12] J. Bai, X. Zhong, S. Jiang, Y. Huang, and X. Duan, Nature Nanotech. 5, 190 (2010).

[13] R. V. Gorbachev, F. V. Tikhonenko, A. S. Mayorov, D. W. Horsell, and A. K. Savchenko, Phys. Rev. Lett. 98, 176805 (2007).

[14] F. V. Tikhonenko, D. W. Horsell, R. V. Gorbachev, and A. K. Savchenko, Phys. Rev. Lett. 100, 056802 (2008).

[15] F. V. Tikhonenko, A. A. Kozikov, A. K. Savchenko, and R. V. Gorbachev, Phys. Rev. Lett. 103, 226801 (2009).

[16] E. McCann, K. Kechedzhi, V. I. Fal'ko, H. Suzuura, T. Ando, and B. I. Altshuler, Phys. Rev. Lett. 97, 146805 (2006).

[17] M. I. Katsnelson, K. S. Novoselov, and A. K. Geim, Nature Phys. 2, 620 (2006). 


\title{
나노패턴된 기판 위에서의 그래핀의 비등방성 전자 수송 특성
}

\author{
칼릴 하피츠 $^{a} \cdot$ 켈렉시 오즈구르 $^{a} \cdot$ 노화용 $^{a *} \cdot$ 시에 야홍 ${ }^{b}$ \\ ${ }^{a}$ 세종대학교 물리학과 및 그래핀연구소, 서울 143-747 \\ ${ }^{\mathrm{b}}$ 캘리포니아주립대학교 재료공학과, 로스엔젤레스, 캘리포니아, 미국 90095 \\ (2011년 8월 3일 받음, 2012년 9월 14일 수정, 2012년 9월 17일 확정)
}

주기적인 나노트랜치 패턴이 있는 기판 위에 놓인 CVD 그래핀의 전도특성을 측정하였다. 나노트랜치에 대해 평행한 방향과 수직한 방향 사이에 전도특성의 큰 비등방성을 발견하였다. 전기 전도의 방향이 나노트랜치에 수직한 경우, 약한 한곳모임의 특성에 있어서도 큰 차이점이 발견되었는데, 이는 퍼텐셜 변조에 의해 생겨나는 전하밀도의 비균일성에 의해 생겨나는 것으로 해석된다.

주제어 : 그래핀, 나노트랜치, 비등방성, 약한 한곳모임

* [전자우편] hnoh@sejong.ac.kr 